\title{
STRUCTURAL EVALUATION OF LOW VOLUME ROAD PAVEMENTS USING PAVEMENT DYNAMIC CONE PENETROMETER
}

\section{K.C. Manjunath ${ }^{1}$, M.S. Amarnath}

'Department of Civil Engineering, the National Institute of Engineering, Mysore - 570 008, Karnataka, India ${ }^{2}$ Faculty of Engineering - Civil, Bangalore University, Jnana Bharathi Campus, Bangalore-560056, Karnataka, India kcmnie@gmail.com, amaranth_ms@rediffmail.com

\section{Abstract}

Static and dynamic cone penetration tests are widely used in Foundation engineering for measuring the penetration resistance of the ground and for relating it to the degree of compaction and safe bearing capacity of soils. In Highway Engineering, Pavement Dynamic Cone Penetrometer (DCP) is used for rapid in-situ strength evaluation of subgrade and other unbound pavement layers. In the present studies, an attempt has been made to identify the strength and thickness of different pavement layers of newly constructed low volume roads in the State of Kamataka, India using dynamic cone penetration studies and was compared with actual resistance of different pavement layers were measured. A Software was used to analyze the DCP duta and to correlate with field observation. The results have favoured the possibility of using dymamic cone penetrometer as a uality control and pavement monitoring tool for low volume roads, eliminating the need for a Benkelman beam or a falling weight deflectometer.

Keywords: Pavement Dynamic Cone Penetrometer, CBR, Subgrade, Rural roads

\section{INTRODUCTION}

Pavement dynamic cone penetrometer is used for rapid in-situ strength evaluation of subgrade and other unbound pavement strength evaluation of subgrade and other unbound pavement layers. It is a simple, economical method, requires minimu situ strength of pavement section and the underlying subgrad layers without the need for digging the existing pavement as in the California Bearing Ratio (CBR) test. The dynamic cone penetrometer consist of an upper fixed $575 \mathrm{~mm}$ travel rod with $8 \mathrm{~kg}$ falling weight, a lower rod containing an anvil, an a replaceable cone with apex angle of $60^{\circ}$ and having diameter of $20 \mathrm{~mm}$. The test is conducted by dropping the weight from $575 \mathrm{~mm}$ height and recording the number of blows for any specified penetration. Then the penetration rate, PR (sometimes referred as DCP ratio, or penetration index PI) is calculated. The DCP has the ability to verify both the leve and uniformity of compaction, which makes it an excellen

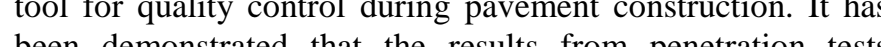
correlate well with the in-situ CBR values. There is a stests correlation between CBR and DCP penetr.ion atio in log-tolog form and CBR-DCP relationship is not significantly affected by changes in moisture content for granular layers. During the past decade, the DCP test has been correlated to many engineering properties such as the CBR, shear strength of granular materials, and most recently, Subgrade Resilient Modulus (MR), Elastic Modulus (E) and the soll classification

\section{LITERATURE REVIEW \\ DCP tests are designed to estimate the structural capacity of pavement layers and embankments. Livneh et al. (1989) well with the in-situ CBR values [1]. Livneh and Ishai (1987) conducted a correlative study between the DCP values and the in-situ CBR values [2]. During this study, both CBR and DCP tests were done on a wide range of undisturbed and compacted fine-grained soil samples, with and without saturation in the laboratory. Field tests were performed on natural and compacted layers representing a wide range of potential pavement and subgrade materials. The research resulted in the quantitative relationship between the CBR of the material and its DCP-PR value and is shown in Eqn. 1 .}

$$
\log \mathrm{CBR}=2.2-0.71(\log \mathrm{PR})
$$

Harrison (1986) also found that there is a strong correlation between CBR and DCP penetration ratio in log-to- log form. He reported that CBR-DCP relationship is not affected by changes in moisture content and dry density [3]. Kleyn (1975) respectively to estimate have suggested the Eqn. 2 and cone Penetration values ( $\mathrm{mm} / \mathrm{blow}$ )

$\log \mathrm{CBR}=2.62-1.27 \log \mathrm{PR}$

$\log \mathrm{CBR}=2.56-1.15 \log \mathrm{PR}$ 
For a wide range of granular and cohesive materials, the US Army Corps of Engineers and Minnesota Department of Transportation [5] have recommended the equations in the form,

$$
\log \mathrm{CBR}=2.465-1.12(\log \mathrm{PR})
$$

$$
\mathrm{CBR}=292 /(\mathrm{PR})^{1.12}
$$

Chen et al. (2001) indicated that the DCP can be useful when the Falling Weight Deflectometer (FWD) back-calculated resilient moduli is not accurate, such as when the asphat concrete layer thickness is less than $75 \mathrm{~mm}$ or when bedrock is shallow [6,7]. The subgrade resilient modulus, which is used in design methods based on structural analysis, can be modulus (Es) and CBR or can be predicted dieen subgrade DCP rests. The 1993 AASHTO Guide for Design of Pavement Structures has adopted the Eqn. 6 for calculating subgrade resilient modulus (MR), which was proposed by Huekelom and Klomp (1962).

$\mathrm{MR}(\mathrm{MPa})=10.34 * \mathrm{CBR}$

The resilient modulus from which this correlation was developed is limited to fine-grained soils with a soaked CBR of 10 or less [8]. Powell et al. (1984) suggested relationsh between subgrade resilient modulus and CBR as shown in Eqn. 7. Other Equations relate the DCP Penetration Ratio (PR) with the subgrade modulus directly. Pen (1990) suggested the two relationships between the subgrade elastic modulus (Es) and PR in (mm/blow) as defined in Equations 8 and 9 [9].

$\mathrm{MR}(\mathrm{MPa})=17.58 \times \mathrm{CBR}^{0.64}$

$\log (\mathrm{Es})=3.25-0.89 \log (\mathrm{PR})$

$\log (\mathrm{Es})=3.652-1.17 \log (\mathrm{PR})$

A number of agencies are using the DCP to assess the strength and uniformity of highway structures. Minnesota Department of Transport (MnDOT) in US specified that the in-situ subgrade CBR based on DCP tests should be at least six to minimize rutting damage to the finished grade (prior to paving) and to provide adequate subgrade support for proper compaction of the base and other layers. In addition, they specified that soils with PR values greater than $25 \mathrm{~mm} / \mathrm{blow}$ may need remedial procedures, such as sub-cutting, drying and compaction, backfilling with granular borrow or lime treatment. From an investigation of a series of case histories in Herfordshire, U.K., in which the DCP has been used, Huntley (1990) suggested a tentative classification system of soll based on penetration resistance, $\mathrm{n}$ in blows per $100 \mathrm{~mm}$ table with considerable caution until a better understanding of the mechanics of skin friction on the upper drive rod is established.

\section{PRESENT INVESTIGATIONS}

To carry out evaluation of low volume road pavements using Pavement Dynamic Cone Penetrometer, newly constructed rural roads (low volume roads) were selected. The roads which were one year old or less than one year were grouped selected for pavement evaluation studies. The roads sected have been widely distributed in Karntaka covering differen soil types, traffic and environmental condition Inventory studies were carried out to collect information regarding the width of the pavement, width of the shoulders on both left and right side of the pavement, the condition of drains and thickness and type of the pavement layers. In addition, the data regarding shoulder condition, depth of water table from the pavement surface, type of vegetation on either side of the test stretch etc were collected and recorded. To monitor the structural condition of the selected pavement test stretches for a specified duration dynamic cone penetration studies were planned.

\subsection{Dynamic Cone Penetration Studie}

The DCP tests were carried out on ten selected pavement test stretches, at two locations each, one on left wheel path and another on right wheel path. To carry out DCP test at a location, the equipment was placed above the pavement over a neat and even surface. Initial scale reading was noted and an eight $\mathrm{kg}$ hammer was dropped from a height of $575 \mathrm{~mm}$. For every 5 blows, scale reading was recorded. The test was carried out till the penetration cone penetrates to a sufficient depth of subgrade. The readings were recorded in a standard format. After the DCP test; a section of pavement near shoulder was cut open to measure the thickness of different
layers of pavement and also to collect the soil sample for layers of pavement and also to collect the soil sample for
laboratory analysis. The same procedure was repeated for all laboratory analysis.
the test sections.

A Software was used to analyze the DCP data and to correlate with field observations. The results of the penetration test were analyzed using software called "UK DCP 3.1". The pavement layers and thickness of each layer along with CBR values with graphical cross sectional details were the outpu section are shown in Table 1 and Fig. 1 respectively. The results were checked with manual method. DCP values for base, sub-base and subgrade along wheel paths for selected pavement test stretches measured during five cycles of field studies are shown in Table 2.

\section{RESULTS AND DISCUSSION}

The strength and thickness of pavement layers of ten newly constructed rural roads in the State of Karnataka, India were 
measured using Pavement Dynamic Cone Penetrometer. For measured using Pavement Dynamic Cone Penetrometer. For each pavement test stretch, four layers of different pavement
composition were identified. The top layer of thin pre-mix carpet resting over a base course, a granular sub-base course and compacted subgrade have been identified. The thickness of four layers varied in all the pavement test stretches. The thickness of base course varied in the range of $118 \mathrm{~mm}$ to 166 $\mathrm{mm}$ and the thickness of granular sub-base varied in the range of $76 \mathrm{~mm}$ to $175 \mathrm{~mm}$. The compacted thickness of subgrade varied in the range of $100 \mathrm{~mm}$ to $210 \mathrm{~mm}$. Although pavement dynamic cone penetrometer does not directly indicate base or a sub base layer, these layers have to be identified by resistance offered to penetration. During experimental investigations the measured thickness of different paventest layers for different pavennent test stretches thickness.

When pavement layer thickness measured using DCP was compared with actual measurement, the variation in result was studies were conducted on wheel paths, but sections were cut open near the edges close to test locations. This clearly indicates the DCP test results are comparable with actual measurements.

Table 1 A typical input and out put data of penetration test for a pavement stretch

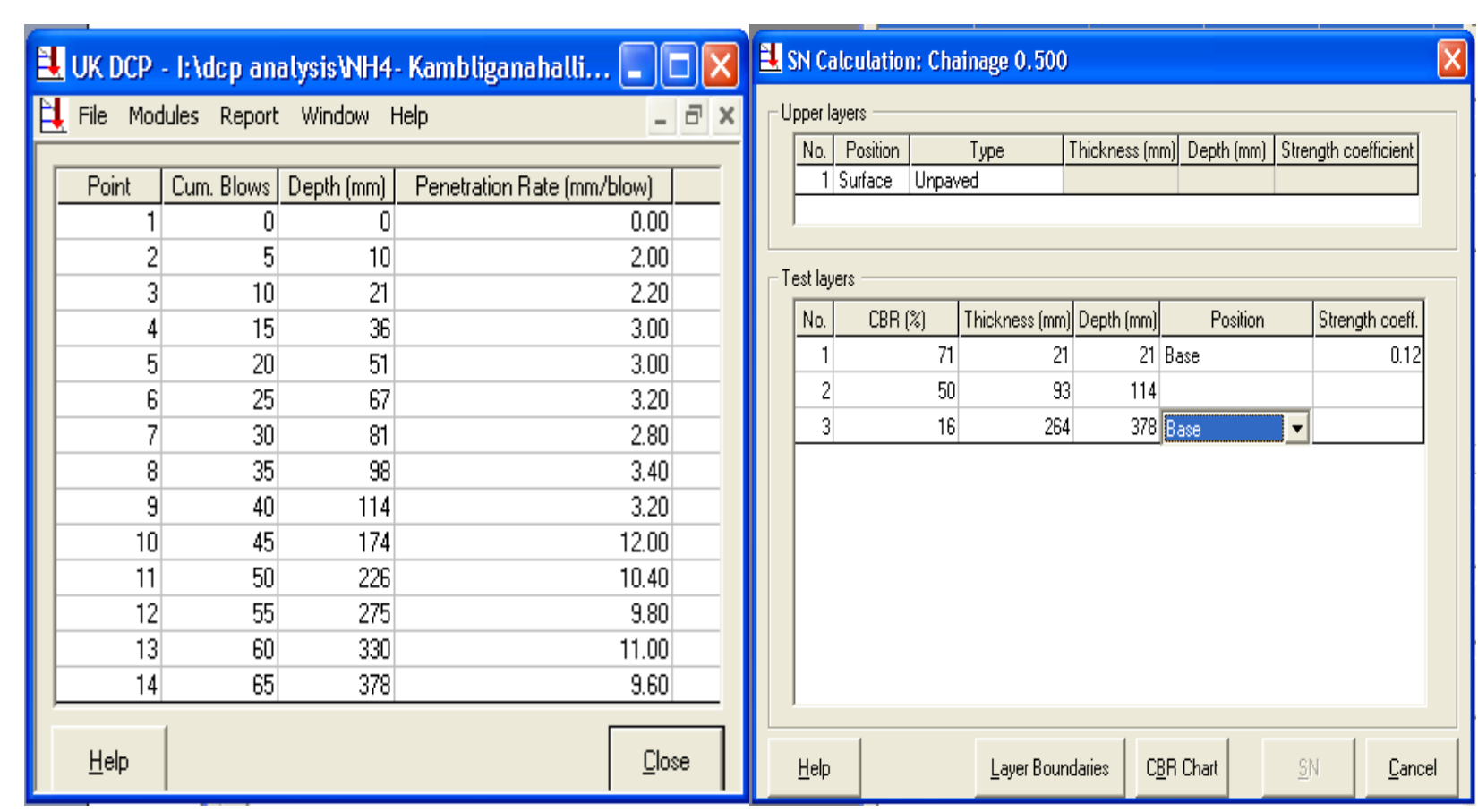




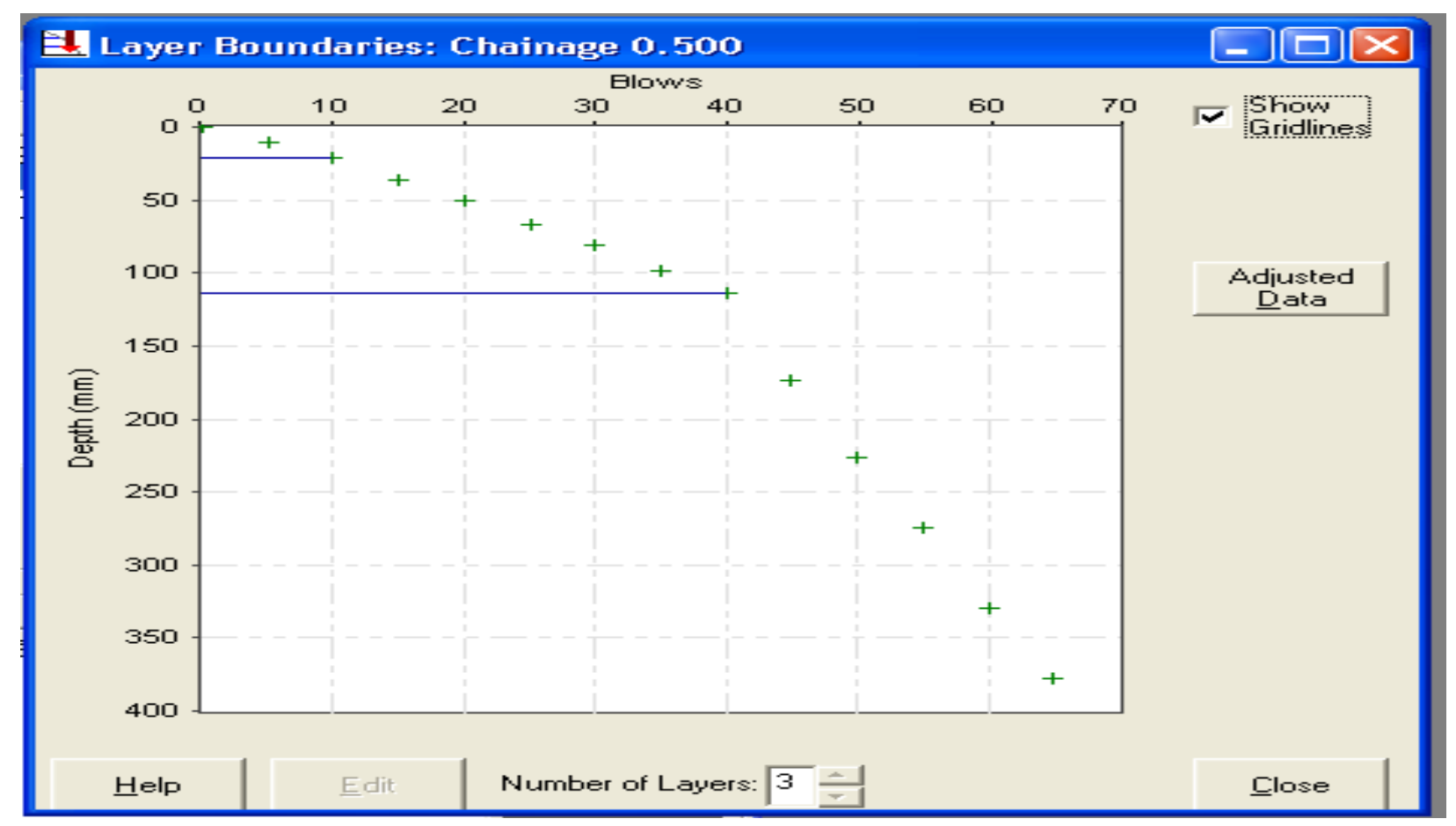

Fig.1 A typical output for a pavement stretch using UK DCP software

\section{CONCLUSIONS}

1. Dynamic Cone Penetrometer can be effectively used to identify number of pavement layers, thickness of each layer
and strength of each layer in terms of CBR for rural roads. The field investigations have indicated that the DCP results and actual measurements vary within 10 percent.

2. Dynamic Cone Penetrometer has the potential to be used as a monitoring tool to evaluate the quality of pavement construction.

3. DCP tests can be used to evaluate the structural condition of the rural road pavements eliminating the need for Benkelman beam or a falling weight deflectometer.

4. A number of trials are required at each location on a tes stretch to get meaningful DCP results. Hence the use of DC test for evaluating studies will be tedious and suitable for subgrade and pavements free of larger sized aggregates. 5. The DCP test can be conducted only on ugbound layers and pavsuito to evalute the structur condition of binest is concrete (BC) and semi-dense bituris concete (SDBC) 6. The DCP results have indicate

deterioration (20 to 30 percent) for selected low vint structura road) test stretches within a period of 2 years. A small increase in penetration resistance of compacted subgrade has been noticed and this can be attributed to further compaction due to exposure to wheel loads.

\section{REFERENCES}

[1] Livneh, M. (1989). "Validation of Correlations between a Number of Penetration Tests and In- situ California Bearing Ratio Tests", TRR 1219.

[2] Livneh, M., and Ishai, I. (1987). "Pavement and Material Evaluation by a Dynamic Cone Penetrometer", Proceedings of the Sixth International Conference on the Structural Design of Asphalt Pavement', Vol. 1, Ann Arbor, Michigan, pp. 665-674.

[3] Harrison, J.A. (1986). "Correlation of CBR and Dynamic Cone Penetrometer Strength Measurement of Soils", Australian Road Research, June 1986, Vol. 16, No.2 pp130-136.

[4] Kleyn, E. G. (1975). "The Use of the Dynamic Cone Penetrometer (DCP)", Report 2/74, Transvaal Roads Department, Pretoria.

[5] Burnham, T. (1996). "Application of the Dynamic Cone Penetrometer to MnDOT's Pavement Assessmen Minnesota Road Research.

6] Chen, D. H., Wang, J. N., Bilyeu, J. (2001) "Application of the DCP in Evaluation of Base and Transportation Research Board, January 2001, Washington, D.C.

[7] Chen, J., Hossain, M., LaTorella, T. (1999). "Use of Falling Weight Deflectometer and Dynamic Cone Penetrometer in Pavement Evaluation", 78th Annual 
Transportation Research Board Meeting, Washington

[8]

Teukelom, W. and Klomp, A.J.G. (1962). "Dynamic Testing as Means of Controlling Pavements During an International Conference on Structural Design of Asphalt Pavement, University of Michigan.

Table 2 Mean DCP values along wheel paths for selected pavement test stretches

\begin{tabular}{|c|c|c|c|c|c|c|c|c|c|c|c|c|c|c|c|}
\hline \multirow[b]{3}{*}{ Sl.No } & \multicolumn{15}{|c|}{ Mean DCP Values, mm/blow } \\
\hline & \multicolumn{3}{|c|}{ May, 2008} & \multicolumn{3}{|c|}{ Dec., 2008} & \multicolumn{3}{|c|}{ May, 2009} & \multicolumn{3}{|c|}{ Dec., 2009} & \multicolumn{3}{|c|}{ May, 2010} \\
\hline & $\begin{array}{l}\text { Bas } \\
\mathrm{e}\end{array}$ & $\begin{array}{l}\text { Sub- } \\
\text { base }\end{array}$ & $\begin{array}{l}\text { Sub } \\
\text { grade }\end{array}$ & $\begin{array}{l}\text { Bas } \\
\mathrm{e}\end{array}$ & $\begin{array}{l}\text { Sub- } \\
\text { base }\end{array}$ & $\begin{array}{l}\text { Sub } \\
\text { grade }\end{array}$ & $\begin{array}{l}\text { Bas } \\
\text { e }\end{array}$ & $\begin{array}{l}\text { Sub- } \\
\text { base }\end{array}$ & $\begin{array}{l}\text { Sub } \\
\text { grade }\end{array}$ & Base & $\begin{array}{l}\text { Sub- } \\
\text { base }\end{array}$ & $\begin{array}{l}\text { Sub } \\
\text { grad } \\
\mathrm{e}\end{array}$ & $\begin{array}{l}\text { Bas } \\
\mathrm{e}\end{array}$ & $\begin{array}{l}\text { Sub } \\
- \\
\text { bas } \\
\text { e }\end{array}$ & $\begin{array}{l}\text { Sub } \\
\text { grade }\end{array}$ \\
\hline 1 & 3.2 & 4.1 & 12.0 & 2.2 & 4.2 & 11.5 & 2.6 & 4.3 & 10.7 & 3.1 & 4.4 & 10.3 & 3.5 & 5.1 & 10.0 \\
\hline 2 & 3.2 & 5.5 & 11.9 & 3.5 & 6.2 & 11.0 & 3.3 & 7.0 & 10.5 & 3.5 & 7.5 & 10.3 & 3.9 & 8.0 & 9.9 \\
\hline 3 & 3.7 & 6.9 & 12.6 & 4.2 & 6.6 & 11.9 & 4.2 & 6.7 & 11.5 & 4.0 & 7.9 & 11.6 & 4.6 & 8.5 & 11.2 \\
\hline 4 & 3.5 & 6.2 & 10.9 & 4.4 & 6.5 & 10.7 & 4.9 & 6.8 & 10.0 & 5.4 & 5.5 & 9.6 & 5.0 & 7.2 & 9.1 \\
\hline 5 & 3.7 & 4.9 & 10.0 & 2.1 & 5.2 & 9.2 & 2.1 & 5.0 & 10.0 & 3.9 & 5.7 & 9.6 & 4.3 & 6.5 & 9.1 \\
\hline 6 & 3.7 & 6.1 & 12.5 & 2.3 & 6.0 & 12.0 & 2.6 & 5.3 & 11.5 & 3.7 & 5.9 & 11.8 & 4.5 & 7.1 & 10.9 \\
\hline 7 & 2.3 & 5.5 & 15.9 & 1.5 & 4.9 & 15.0 & 2.2 & 7.4 & 16.0 & 2.4 & 8.2 & 14.7 & 3.2 & 9.1 & 13.2 \\
\hline 8 & 1.5 & 3.7 & 11.6 & 2.1 & 5.5 & 12.5 & 2.5 & 5.6 & 12.0 & 4.6 & 6.7 & 11.3 & 5.1 & 8.1 & 10.5 \\
\hline 9 & 2.7 & 4.2 & 13.9 & 2.6 & 4.5 & 12.5 & 2.5 & 4.5 & 12.0 & 2.4 & 5.4 & 12.6 & 2.8 & 7.1 & 11.2 \\
\hline 10 & 3.2 & 6.2 & 15.0 & 2.2 & 5.1 & 12.3 & 2.6 & 5.0 & 12.5 & 3.8 & 6.6 & 9.6 & 4.2 & 7.8 & 8.9 \\
\hline Mean & 3.0 & 5.3 & 12.6 & 2.7 & 5.5 & 11.9 & 2.9 & 5.7 & 11.7 & 3.7 & 6.4 & 11.1 & 4.1 & 7.5 & 10.4 \\
\hline
\end{tabular}

